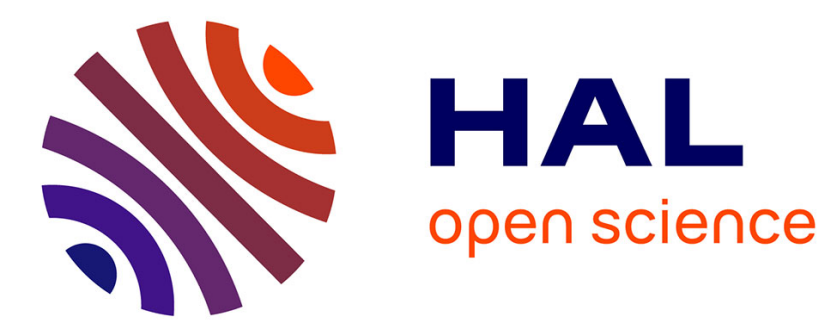

\title{
Investments in Quality, Collective Reputation and Information Acquisition
}

Fulvio Fontini, Katrin Millock, Michele Moretto

\section{To cite this version:}

Fulvio Fontini, Katrin Millock, Michele Moretto. Investments in Quality, Collective Reputation and Information Acquisition. 2013. halshs-00825782

\section{HAL Id: halshs-00825782 \\ https://shs.hal.science/halshs-00825782}

Submitted on 24 May 2013

HAL is a multi-disciplinary open access archive for the deposit and dissemination of scientific research documents, whether they are published or not. The documents may come from teaching and research institutions in France or abroad, or from public or private research centers.
L'archive ouverte pluridisciplinaire HAL, est destinée au dépôt et à la diffusion de documents scientifiques de niveau recherche, publiés ou non, émanant des établissements d'enseignement et de recherche français ou étrangers, des laboratoires publics ou privés. 


\section{Documents de Travail du Centre d'Economie de la Sorbonne}

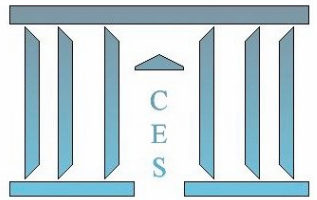

Investments in Quality, Collective Reputation and Information Acquisition

Fulvio FonTini, Katrin MiLlocK, Michele MoRETTO

2013.44

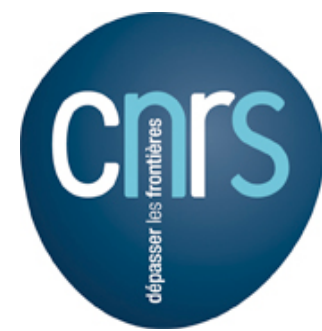




\title{
Investments in Quality, Collective Reputation and Information Acquisition
}

\author{
Fulvio Fontini* Katrin Millock ${ }^{\dagger} \quad$ Michele Moretto* \\ May 5, 2013
}

\begin{abstract}
In many cases consumers cannot observe firms' investment in quality or safety, but have only beliefs on the average quality of the industry. In addition, the outcome of the collective investment game of the firms may be stochastic since firms cannot control perfectly the technology or external factors that may affect production. In such situations, when only consumers' subjective perceptions of the industry level of quality matters, the regulator may make information available to firms or subsidize their information acquisition. Under what conditions is it desirable to make information available? We show how firms' overall level of investment in quality depends upon the parameters of the quality accumulation process, the cost of investment and the number of firms in the industry. We also show the potentially negative effects on the total level of quality from providing information on consumers' actual valuation.
\end{abstract}

J.E.L. Classification: C73, D92, L15, Q52.

Keywords: collective reputation, option value, quality.

\footnotetext{
*Department of Economics and Management. University of Padua, Italy.

†Paris School of Economics, CNRS, Centre d'Economie de la Sorbonne. Corresponding Author: Maison des Sciences Economiques. Université Paris 1 Panthéon-Sorbonne, 106/112, Boulevard de l'Hopital, 75647 Paris Cedex 13.
} 


\section{Introduction}

In real investment problems it is often the case that firms' investments in improving product characteristics cannot be directly observed by consumers. This is the case of so called credence goods (Darby and Karni, 1973), i.e., goods that consumers cannot discriminate ex ante by focusing on specific elements when assessing their demand. In several cases credence goods are characterized by collective production, in the sense that they are the result of some production activity that depends on the behaviour of the entire industry rather than on the investment undertaken by a single firm. This happens when an individual tag or label cannot be attached to the production of a given firm within the industry, when consumers' perceptions of the good depends more on the common behaviour of all firms in the industry rather than the specific action or reputation of one of them, or when the production chain itself is the result of the common effort of all participants in a given venture. Consider, for instance, the investment in quality for the production of an agricultural good that is perfectly homogeneous but can be characterized according to a given localization or type of input supplied to the production chain. Examples include the European protected geographical indication and protected designation of origin labels, or state product labels in the US (such as Washington apples, Idaho potatoes and Florida oranges). Or consider an industry where reputation depends more on the intrinsic characteristics of the production chain rather than on the individual behaviour, as is the case of the safety reputation for some complex industrial production, e.g., the oil and gas industry. Consumers' concerns about oil extraction, for instance, seem to be related more to the technology itself rather than the reputation of a given supplier. Another example, yet different from the first two, might be the case of an investment consortium set up to develop a research activity. In all these cases, there is a collective supply of some input (effort, feedstock, money, etc.) by all participants in the industry that generates

positive externalities for any firm in the industry. These externalities affect 
firms' returns, depending on consumers' ability to effectively evaluate and integrate into their own demand the consequences of firms' investment.

Investments in quality, effort, and research generate consequences that are not ex ante observable, but only predictable. The impact that these investments have on firms' return is stochastic for two main reasons. First, the outcome of the investment can depend on the realization of some external factor that is not under control of the single firm. Consider, for instance, the case of the protected designation of origin labels, in which a systemic disease or weather conditions might impact the quality of the feedstocks supplied to the consortia that supervise the production chain. It might also be the case of the random outcome of a research activity (that is ex ante uncertain by definition) or the random occurrence of a systemic event that affects the industry's reputation as regards safety or reliability. One example was the manner in which mad cow disease affected the entire market demand for meat. The second source of uncertainty stems from the fact that the collective investments are beneficial for the firm only to the extent that consumers realize the positive improvement in quality or safety and reward firms in a given industry accordingly, thereby increasing demand for the product. The objective of the paper is to study investments, such as those in collective reputation, whose outcome is not directly observable, but only their consequences ex post. In these cases what matters for consumers' choice and ultimately for firms' returns is consumers' perception of the collective effort, rather than its effective level. Consumers might experience goods with a certain time lag, or be affected by subjective prejudices, expectations or attitudes, that may be important at the time of the purchase. Therefore, consumer attitudes can reinforce or weaken the consequences that the collective effort effectively generates in terms of improving the quality of the good, finding a new good or process, and improving firms' reputation or reliability. Hence, firms' investments are plagued not only with an objective 
(systemic) uncertainty about the result of their effort, but also with a subjective one, depending on consumers' attitudes and perceptions. Firms who are characterized by a positive (negative) perception by consumers are rewarded (penalized) in terms of an increase (reduction) of their demand.

Typically, firms might send signals to consumers through advertising and labelling, or might try to build on their reputation in order to improve the consumers' perception. We do not follow these approaches here, as they have already been thoroughly explored in the literature (see the survey by Dranove and Jin, 2010). On the contrary, we are interested in evaluating to what extent relieving firms' uncertainty can be beneficial for both the firms themselves and the society as a whole. For this, we assume that the uncertainty about consumers' valuation of quality can be resolved by paying a fee to run a market research survey, for instance. We investigate to what extent this possibility affects firms' value, their choice of acquiring the information, as well as overall quality accumulation over time. This latter point is motivated by the consideration that the type of investments we analyze here often implies positive externalities not just for the industry involved, but for society. It may therefore be desirable to increase investment in product quality, research, firms' safety or reliability, regardless of the benefit for a given firm or the industry. However, when the investment generates a collective good for the firms that operate in the industry, their individual investment decision problem is quite complex. On the one hand, each firm has to take into account the strategic behaviour of all other firms when deciding on how much to invest in the production of the collective good. On the other hand, there exists a twofold uncertainty that affects its possibility to recoup its expenses through an increase in demand and profits. Such an investment problem is the target of our study. As mentioned, we tackle it from both the standpoint of firms' value, as well as from quality accumulation. In order to do so, we define the firms' investment problem and analyze a dynamic in- 
vestment game in a collective good that has a positive externality. From now onward, for the sake of simplicity, we will refer to such a good as "quality". We set up a model in which the total quality that results from the collective investment problem is stochastic. Quality affects firms' profits by increasing individual demand but the amount of such an increase is also random, since it depends on consumers' perception of the quality level. We consider the possibility for the firms of paying a fee to eliminate the latter source of uncertainty, for instance through paying a fee to acquire information on consumers' valuation of the aggregate quality from a market research company. We study if and how much such a possibility is going to affect firms' quality investment decisions, firm value and ultimately the overall level of quality generated. Finally, to focus on the probability of quality adoption by firms from a public perspective, we evaluate to what extent facilitating the acquisition of such information can be beneficial for speeding up the process of quality creation. The paper is structured as follows. After the introduction, the next Section discusses the related literature. The model is introduced in Section 2. Section 3 characterizes the solution to the firms' quality investment game without information acquisition, whereas Section 4 solves the investment decision problem with information acquisition. In Section 5 we consider the quality accumulation problem, and investigate whether it is ex ante optimal for an external body, who can allow or restrain firms to acquire information, to do so when information acquisition either is costly or costless. Conclusions and indications of future research follow. All proofs are presented in the Appendix.

\subsection{Discussion of the related literature}

Our analysis draws on three different strands of the literature: the literature on quality and collective reputation, investment theory under stochastic production and the literature on regulation through information disclosure. Tirole (1996) first investigated collective reputation in the context of worker 
matching. It has since been applied in many fields, notably trade in agricultural commodities and other products that are not easily distinguishable ex ante (Winfree and McCluskey, 2005; McQuade et al., 2010), but always in a deterministic framework. Recent work on stochastic quality, on the other hand, normally assumes that a firm can signal the quality of its product (high or low) such that its own reputation matters, not the collective reputation. In Board and Meyer-ter-Vehn (2011) reputation is defined as consumers' belief that the product quality is high. Dilme (2011) and Bohren (2011) studies the cumulative effect of past investments on current quality in a stochastic game, but also here, in a game between one firm and multiple consumers. We extend the analysis of a firm's investment decision in quality and the dynamics of the collective reputation of firms by analyzing a dynamic game with stochastic quality. The model we develop extends the existing analysis by allowing the quality level to be stochastic both in the level of the investment and in the impact that quality has on firms' demand. ${ }^{1}$ We share with Claude and Zaccour (2009) the specification of how reputation shifts aggregate demand and the collective build-up of a stock of quality. But, also here, we depart in our assumption of the stochastic nature of quality.

It is natural to interpret quality as environmental quality or safety, or other credence good characteristics. Whereas there is little modeling on the consequences of firms' information acquisition, some theoretical modeling has been done of information disclosure on safety or environmental quality. Kennedy et al. (1994) analyze the conditions under which information disclosure of a consumption externality can be welfare-enhancing when consumers form expectations of the aggregate environmental damage. Their model concentrates on the consumer's choice only and does not investigate the consequences of information acquisition on the firm. Petrakis et al. (2005) extend the analysis of information disclosure as a policy option to include

\footnotetext{
${ }^{1}$ Static analyses by Fleckinger, 2007, and McQuade et al., 2010, focus on the impact of market structure and of regulation, such as minimum quality standards.
} 
also an environmental externality and consideration of the market structure and show how the combination of environmental taxes and information disclosure leads to higher welfare than either instrument on its own. Sartzetakis et al. (2012) analyze the build-up of the information available to consumers over time and how it interacts with the setting of an optimal environmental tax. The existing literature thus focuses on consumers' use of information disclosure programmes, whereas the focus of the current article is the impact of information acquisition on firms' investment in quality.

Our approach is also related, at least from a theoretical point of view, to the models in the literature on R\&D collaboration (based on the seminal models of d'Aspremont and Jacquemin, 1988, and Kamien et al., 1992). Indeed, the model that we develop here on the investment in collective reputation can describe well an R\&D problem where the collective good might be, for instance, the overall level of financial commitment of the participants to a research consortium. In this case, the problem of the subjective perception of consumers that might reduce or increase the impact that research has on firms' demand is indeed the case of a trial that allows firms to realize the market potential of a given research project. From this point of view, we extend the literature by explicitly considering the free rider problem in a dynamic stochastic framework, i.e., analyzing a dynamic investment game under uncertainty. ${ }^{2}$

Methodologically, the paper that is the most closely related to ours is Wirl (2008) who studies a stochastic dynamic game among firms that create a stock externality that is subject to uncertainty over time. By comparison to that model we share the context of a dynamic game among firms but we develop the model to include aspects of information availability that are absent in such dynamic games. In particular, we introduce uncertainty also on consumers' perceptions on the quality of the good and evaluate the value

\footnotetext{
${ }^{2}$ Recent dynamic models of positive spillovers from R\&D models are all deterministic to our knowledge (for example Hinloopen et al., 2011).
} 
to firms of acquiring that information.

\section{The model}

Consider an industry composed of $n$ risk-neutral identical firms that produce a good whose market price is affected by the level of reputation $R$ of the industry as a whole. That is, the level of $R$ determines the location of the inverse demand curve, as in Winfree and McCluskey (2005) and Claude and Zaccour (2009). We further assume that, although the firms may invest in product quality to increase their collective level of reputation, they are unable to trace exactly how consumers convert product quality into reputation but can only form expectations on that.

We make the following assumptions about the industry:

Assumption 1 Each firm produces one unit of output to be sold in a market where the inverse demand function depends positively on the level of reputation of the whole industry. We adopt a linear functional as:

$$
p(R)=a+R
$$

where $a>0$ is an index that can be viewed as the relative strength of the market demand. We thus deliberatively abstract from firms' other strategic interactions, such as the quantity choice, in order to focus the analysis on the provision of quality as a collective good problem.

Assumption 2 Even if consumers are willing to pay a higher price for the product produced by firms with higher reputation for quality, firms are unable to trace exactly how much their investment contributes to increase reputation. This relation is linear for simplicity:

$$
R=(1+\theta) Q
$$


where $Q$ is the stock of quality and $\theta$ is a stochastic variable with density $f(\theta), \theta \in[-1,+1]$ and $E(\theta)=0 .{ }^{3}$ We believe there is no reason to suppose ex ante that consumers have any positive or negative bias towards reputation, therefore we assume that $\theta$ is symmetrically distributed around its mean.

Substituting (2) in (1) we get: $p(Q, \theta)=a+(1+\theta) Q$. Since $\theta$ must be understood to represent consumers' specific perception of the product quality, the main issue is the information that the firms possess. In this respect we add the following assumption:

Assumption 3 Firms have common knowledge and observe perfectly the evolution of $Q$, but they do not know the realization of $\theta$. Furthermore, although firms can observe total quality, we assume that they cannot infer $\theta$ from observing the price.

Assuming that firms cannot infer $\theta$ from observing the past relations of $p$ and $Q$, is tantamount to assume that either $(i)$ they must have some form of limited recall or knowledge, i.e., a limited memory of past occurrences or (ii) the term $a$ has a stochastic component that cannot be observed by the firms. ${ }^{4}$

Assumption 4 Each firm may improve the level of reputation of the industry as a whole by investing each time an amount $k_{i}, i=1,2 \ldots n$, in the

\footnotetext{
${ }^{3}$ The support of $\theta$ can be $[\theta, \bar{\theta}]$ without affecting the results. But as seen from Equation (2), as long as $Q>0, R \geq 0$ if and only if $\theta \geq-1$.

${ }^{4}$ For instance, we could assume, as in Claude and Zaccour (2009), a simple linear inverse demand curve:

$$
p=A+R-C X
$$

where $p$ is the output price per unit, $X$ is the total output, $A$ is an exogenous shock to demand and $C$ is a non-negative constant representing the slope of the linear demand function. Setting $a=A-C X$ we would obtain the expression (1) in the text.
} 
quality of the product. We assume that the stock of quality $(Q)$ evolves over time according to the following stochastic differential equation:

$$
d Q=g\left(\sum_{i=1}^{n} k_{i}\right) Q d t+\sigma Q d z, \quad Q_{0}=Q
$$

where $d z$ are identically and independently distributed according to a normal distribution with mean zero and variance $d t$. There are several reasons why the level of product quality is stochastic: uncertainty over the adopted technology, external occurrences (for instance weatherrelated events), and similar unmanageable causes. Assuming a stochastic evolution of quality over time is rather standard and the assumption of a Brownian motion is shared by several analyses of a single firm's investment problem (e.g., Faingold and Sannikov, 2011, Bohren, 2011). Since we aim at analyzing the collective reputation of a set of firms, the drift term $g\left(\sum_{i=1}^{n} k_{i}\right)$ is a function of the aggregate level of investment in quality at time $t$, with $g^{\prime}\left(\sum_{i=1}^{n} k_{i}\right)>0$ and $g(0)=0$, while the instantaneous variance $\sigma$ is constant. For the rest of the paper we assume that $g\left(\sum_{i=1}^{n} k_{i}\right)=\alpha\left(\sum_{i=1}^{n} k_{i} / n\right)$, with $\alpha \in[0,1]$. It seems reasonable to assume that only a fraction of new investment in quality accumulates over time. The assumption on average quality is used also in a deterministic framework in Winfree and McCluskey (2005) and in McQuade et al. (2010) who use a quantity-weighted average of the qualities sold by the firms. Indeed, consumers only have an idea of average quality since they cannot distinguish individual contributions to quality. This assumption is supported by the empirical work by Landon and Smith (1997, 1998). Furthermore, for sake of simplicity, equation (3) is further simplified by assuming that each firm invests at a fixed level, i.e., $k_{i} \in\{0,1\}$ for all $i$.

Assumption 5 The investment in quality is totally irreversible. The firms may improve product quality by adopting a new technology, devoting 
resources to acquire a new production process or simply investing in research. These investment activities are considered to be productspecific and sunk. Therefore, at each point in time the firm has the choice (strategy) to make a sunk investment in quality or not at cost $c>0$. Furthermore, decay is assumed to be zero. ${ }^{5}$

The analysis is conducted using feedback stationary Markov strategies: $k_{i}=\Psi_{i}(Q)$, for $i=1,2 \ldots n$. This implies that at time $t$ the firms' actions depend only on the current state of information, i.e. the accumulated stock of quality. In addition the symmetry implies that $k_{i}=\Psi(Q)$ for all $i$ and the best reply to $\Psi^{-i}$ is a Nash equilibrium. ${ }^{6}$

\section{Incomplete information with no information acquisition}

If information on $\theta$ cannot be acquired neither ex-ante nor ex post, the firm makes a decision which is based on the expected value of $\theta$. Obviously, without information there is no reason to believe that either a positive or negative bias exists, and therefore its expected value is set equal to zero. Assuming profit maximizing behaviour, each firm chooses the level of investment in quality that maximizes the expected present value of its stream of profits over time, subject to the state equation (3). If we denote the discount rate

\footnotetext{
${ }^{5}$ In order to make the model more realistic, we could also introduce quality depreciation, for instance, by assuming that quality lifetime follows a Poisson process. This would mean that, over any short period $d t$, there would be a given probability that $Q$ got reduced or even completely cancelled. Since the effect of depreciation would be making irreversibility weaker, i.e., investment in quality would not be eternal, none of the results of the paper would be affected by such an assumption.

${ }^{6}$ Since the strategy equation $k_{i}=\Psi(Q)$ is derived by the firm's non-cooperative intertemporal optimization (see Section 3 below), each firm behaves optimally for all values of $Q$ regardless of whether this stock was on or off the equilibrium path (Basar and Olsder, 1995).
} 
by $r(r>\alpha)$, the firm's objective is:

$$
\begin{aligned}
V(Q) & =\max _{k_{i} \in\{0,1\}} E_{0}\left[\int_{0}^{\infty} e^{-r t} p\left(Q_{t} ; 0\right) d t-\sum_{m} e^{-r T_{m}} c k_{i}\right] \\
\text { s.t. } d Q_{t} & \geq 0 \text { and (3) for all } t \geq 0
\end{aligned}
$$

where $\theta$ is substituted by $E(\theta)=0, c$ is the unit cost of quality, $T_{m}$ indicates the time periods at which the firm invests and $m$ is a counter indicating the number of times the firm invests.

The sufficient condition for a stationary Markov perfect equilibrium is given by the Bellman equation for the firm's non-cooperative intertemporal optimization:

$r V_{i}=\max _{k_{i} \in\{0,1\}}\left[\frac{1}{2} \sigma^{2} Q^{2} V_{i}^{\prime \prime}+g\left(k_{i}+\sum_{j \neq i}^{n} k_{j}\right) Q V_{i}^{\prime}+p(Q ; 0)-c k_{i}\right]$ for $i=1,2 \ldots n$

where $V_{i}^{\prime}$ and $V_{i}^{\prime \prime}$ stand for the first and second derivatives with respect to $Q$ respectively. Recall that because of the binary action space and firms' homogeneity assumption, $V_{i}=V$ for all $i$.

Standard arguments lead to a solution for (5) taking the following form (see Dixit and Pindyck, 1994, and Appendix A):

$$
V(Q ; 0)= \begin{cases}V_{0}(Q ; 0) & \text { for } Q<\hat{Q} \\ V_{1}(Q ; 0) & \text { for } Q>\hat{Q}\end{cases}
$$

where $V_{0}(Q ; 0)$ and $V_{1}(Q ; 0)$ are the firm's value when it is not investing and when it is investing in quality respectively, and $\hat{Q}$ is the stock of quality that triggers the investment. If firms find themselves in a range of quality such that $Q<\hat{Q}$, they would not invest in quality, i.e., would choose $k=0$. This simply means that the overall stock of quality would evolve over time following a purely stochastic path with no drift term (see Equation (3)). If, on the contrary, the overall level of quality was such that $Q>\hat{Q}$, firms would 
find it optimal to invest, i.e., $k=1$. Recall that the stochastic nature of $Q$ is such that firms change their strategy whenever $Q$ crosses $\hat{Q}$. This might happen several times. In other words, even if firms were in a region where they would find it optimal to invest in quality, it might happen that at a certain point in time $Q$ falls below $\hat{Q}$, which implies that firms would stop investing (and vice versa).

Assuming that $\hat{Q}$ exists, substituting the two strategies into the Bellman equation (5) reduces to:

$$
r V_{0}=\frac{1}{2} \sigma^{2} Q^{2} V_{0}^{\prime \prime}+p(Q ; 0) \quad \text { for } Q<\hat{Q}
$$

and

$$
r V_{1}=\frac{1}{2} \sigma^{2} Q^{2} V_{1}^{\prime \prime}+g(n) Q V_{1}^{\prime}+p(Q ; \theta)-c \text { for } Q>\hat{Q}
$$

Provided that $r>g(n)$, solving the problem [6-7] yields the following:

Proposition 1 In the quality investment game, the following holds:

1) The investment rule is:

$$
\hat{Q}=\frac{\left(\beta_{1}-\gamma_{2}\right) \frac{r n}{\alpha}-\gamma_{2} \beta_{1}}{\left(\beta_{1}-\gamma_{2}\right)-\beta_{1}\left(\gamma_{2}-1\right) \frac{\alpha}{r-\alpha}} c>0
$$

2) The value of the firm is:

$$
V(Q ; 0)=\left\{\begin{array}{cc}
A_{0} Q^{\beta_{1}}+\frac{a+Q}{r} \quad \text { for } Q<\hat{Q} \\
B_{1} Q^{\gamma_{2}}+\frac{a}{r}+\frac{Q}{r-\alpha}-\frac{c}{r} & \text { for } Q>\hat{Q}
\end{array}\right.
$$

where:

$$
A_{0}=\left[\frac{n c}{\alpha}-\frac{\hat{Q}}{r}\right] \frac{\hat{Q}^{-\beta_{1}}}{\beta_{1}} \text { and } B_{1}=\left[\frac{n c}{\alpha}-\frac{\hat{Q}}{r-\alpha}\right] \frac{\hat{Q}^{-\gamma_{2}}}{\gamma_{2}}
$$


and: $\beta_{1}=\frac{1}{2}+\sqrt{\left(\frac{1}{2}\right)^{2}+\frac{2 r}{\sigma^{2}}}>1, \gamma_{2}=\left(\frac{1}{2}-\frac{\alpha}{\sigma^{2}}\right)-\sqrt{\left(\frac{1}{2}-\frac{\alpha}{\sigma^{2}}\right)^{2}+\frac{2 r}{\sigma^{2}}}<0$.

Proof. See Appendix A

In (9), in the range where $Q>\hat{Q}$, the term $\frac{a}{r}+\frac{Q}{r-\alpha}-\frac{c}{r}$ is the present value of selling the output when each firm commits to invest forever, while $B_{1} Q^{\gamma_{2}}$ is the value of the option to suspend investment in the future. On the contrary, in the range where $Q<\hat{Q}$, the term $\frac{a+Q}{r}$ indicates the present value of selling the output when each firm chooses not to invest in quality, while $A_{0} Q^{\beta_{1}}$ is the option value of the investment in quality. This latter term represents the benefits each firm expects to obtain by the rivals' future investment in quality. Because the existence of negative spillover due to other firms' possible free riding strategies, such benefits need not necessarily be positive. In particular, inspecting the expression for $A_{0}$ in Equation (10), we note that, as long as $\hat{Q}>0$, the following is true:

$$
\text { If } \frac{\hat{Q}}{n}>\frac{r c}{\alpha} \text { then } A_{0}<0 \text { and } B_{1}>0
$$

while

$$
\text { If } \frac{\hat{Q}}{n}<\frac{(r-\alpha) c}{\alpha} \text { then } A_{0}>0 \text { and } B_{1}<0
$$

In the quality investment game that firms are playing the usual prisoners' dilemma trade-off applies. On the one hand, investing in quality is positive since it increases revenues, but on the other hand each firm is tempted to free ride on the others, given the positive industry spillovers. When $A_{0}<0$, each player, expecting the free-riding behavior of the other firms, anticipates the rivals' moves choosing not to undertake its own investment. This generates a war of attrition game that is harmful for product quality as well as for each player. In fact, the result is the opposite of the one obtained by Wirl (2008) in his study of a dynamic game among firms contributing to the same aggregate externality. ${ }^{7}$ Here, free riding makes firms wait longer before investing since

\footnotetext{
${ }^{7}$ Proposition 6, p. 108 in Wirl (2008).
} 
an increase in $n$ only decreases aggregate quality. On the contrary, if $A_{0}>0$, the positive impact of the investments more than compensates the negative effect of the free-rider problem, inducing a positive value for the investment option.

Similarly, in the range of values for which the free-rider problem dominates the positive spillover from investment, the option to suspend investment adds value to firms' choice even if the firm is not investing, given that it is beneficial to keep alive the possibility of stopping investments: $B_{1}>0$. Symmetrically, the option to stop investing when firms find it beneficial to invest, that is, when the spillovers dominate the free-rider problem, reduces the firms' investment value: $B_{1}<0$.

\section{Investment in information acquisition}

Now consider the case when $\theta$ is not known, but the firms are able to obtain information on the true value of $\theta$ by paying (altogether) a fixed fee $\Phi$. Depending on the market condition, this can be done by the firm before undertaking the investment decision or after having started to invest. Given that we intend to focus on the choice to acquire information per se, and do not want to mix the investment choice with other possible gaming behavior, we assume that no free-riding is possible in the information acquisition choice. A sufficient condition might be, for instance, that the fee for acquiring information has a threshold $\Phi^{*}$ such that $\Phi \frac{n-1}{n}<\Phi^{*}$. In such a case there would be information acquisition only when all firms decide to pay the individual fee $\frac{\Phi}{n}$.

Working backward, we first derive the optimal strategy under full information and then we consider the option value to acquire the information on $\theta$. 


\subsection{Costless information acquisition}

When information acquisition is costless, we are in a case of full information,

i.e., firms can acquire the information on $\theta$ without paying any cost. In such a setting, Equation (4) becomes:

$$
\begin{aligned}
& V(Q ; \theta)=\max _{k_{i} \in\{0,1\}} E_{0}\left[\int_{0}^{\infty} e^{-r t} p\left(Q_{t} ; \theta\right) d t-\sum_{m} e^{-r T_{m}} c k_{i}\right] \text { for } i=1,2 \ldots n \\
& \text { s.t. } d Q_{t} \geq 0 \text { and (3) for all } t \geq 0
\end{aligned}
$$

From which it is easy to prove that:

Proposition 2 Under full information,

1) The optimal trigger is:

$$
\tilde{Q}=\frac{\hat{Q}}{(1+\theta)}
$$

2) and the value of the firm becomes:

$$
V(Q ; \theta)=\left\{\begin{array}{cc}
\tilde{A}_{0} Q^{\beta_{1}}+\frac{a+(1+\theta) Q}{r} & \text { for } Q<\tilde{Q} \\
\tilde{B}_{1} Q^{\gamma_{2}}+\frac{a}{r}+\frac{(1+\theta) Q}{r-\alpha}-\frac{c}{r} & \text { for } Q>\tilde{Q}
\end{array}\right.
$$

where:

$$
\tilde{A}_{0}=\left[\frac{n c}{\alpha}-\frac{\tilde{Q}}{r}\right] \frac{\tilde{Q}^{-\beta_{1}}}{\beta_{1}} \text { and } \tilde{B}_{1}=\left[\frac{n c}{\alpha}-\frac{\tilde{Q}}{r-\alpha}\right] \frac{\tilde{Q}^{-\gamma_{2}}}{\gamma_{2}}
$$

Proof. Straightforward from Appendix A

Note that the firms' value function described above (13) maintains the same structure and characteristics of the case discussed above. In particular, 
the option value of investing $\left(\tilde{A}_{0}\right)$ and of halting investment $\left(\tilde{B}_{1}\right)$ can be negative or positive, according to the parameters of the game. In addition, by (12), it is immediate to show that:

$$
\begin{aligned}
& \tilde{Q} \geq \hat{Q} \quad \text { for } \theta \in[-1,0] \\
& \tilde{Q}<\hat{Q} \text { for } \theta \in(0,+1]
\end{aligned}
$$

This implies that the impact of information on the investment choice is not linear. In particular, information on $\theta$ may foster investment in quality compared to the case when there is no information acquisition, i.e., $\tilde{Q}<\hat{Q}$, if the consumers' uncertainty parameter is such that, once revealed, it shows a positive bias of consumers' quality perception, i.e., if $\theta>0$. On the contrary, information disclosure might slow down the investment in quality, i.e., $\tilde{Q}>$ $\hat{Q}$, if consumers maintain a negative perception of firms' investments, i.e., if $\theta<0$. Obviously, it is never optimal to invest in quality if the quality perception by consumers is the worst possible one, $\theta \rightarrow-1$ (i.e. $\tilde{A}_{0}=0$ and $\tilde{Q}=\infty)$. Figure 1 describes the difference in terms of the stock of quality that triggers the investment in quality with information compared to the case when there is no information acquisition, as a function of the uncertainty parameter $\theta$.

We can see in Figure 1 that the trigger of the investment in the full information case coincides with the one for the no information case only if consumers have no bias (either positive or negative) in their perception of quality, i.e., $\theta=0$. On the contrary, a positive (negative) bias induces firms to invest earlier (later), as expected. The trigger has a lower boundary when the parameter $\theta$ is positive, due to the lowest boundary of any investment trigger, namely $\frac{\hat{Q}}{2}$. Given the structure of the game, when the accumulated quality level is low (below $\frac{\hat{Q}}{2}$ ), the positive spillover of the quality is so low that firms find it optimal not to invest in quality even if they knew that consumers have the highest possible perception of their investment. On the contrary, a 
Figure 1: $\tilde{Q}$ as a function of $\theta$

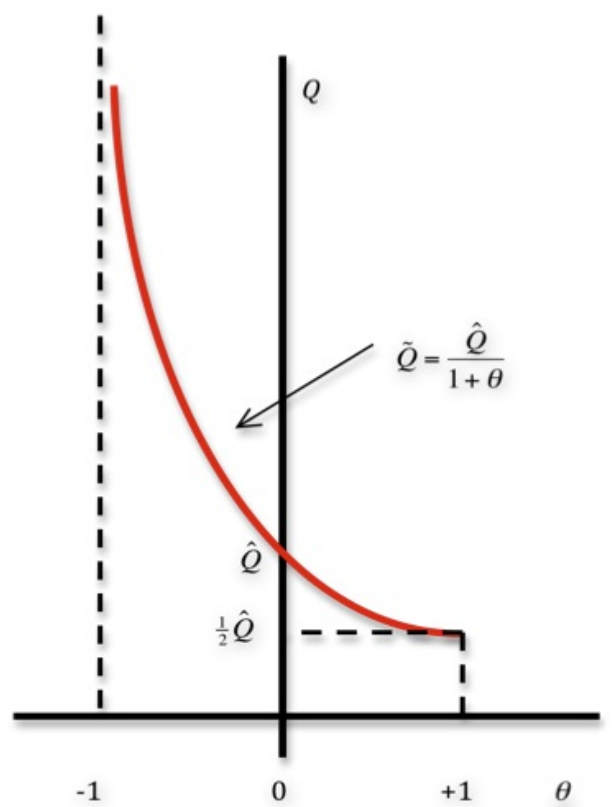


negative bias in consumer perceptions delays the investment decision even if the aggregate quality level is extremely high. In the extreme case, for a fully negative bias firms would never invest. In fact, it is as if firms' investment decisions were penalized more by a negative perception of their quality level by consumers than by a positive one, which might induce a more cautious behaviour by firms.

\subsection{Costly information acquisition}

Let us consider now the case in which firms can obtain information on $\theta$ by paying a fee $\frac{\Phi}{n}$. We assume that firms can choose when to take that decision. A priori, it may occur either before or after they have decided on their own to invest in quality. This implies that there are two decisions that have to be taken and consequently two triggers: one is the trigger of the investment choice without knowing $\theta$ and the other one is the trigger of the information acquisition choice. The first is still $\hat{Q}$ and call the second $Q_{I}$. We consider now the latter.

If we denote by $E_{\theta}[V(Q ; \theta)]-V(Q ; 0)$ the ex-ante value of information, the problem can be managed as suggested by Murto (2004):

$$
I(Q)=\max _{T} E_{0}\left[\left(E_{\theta}[V(Q ; \theta)]-V(Q ; 0)-\frac{\Phi}{n}\right) e^{-r T}\right],
$$

where $I(Q)$ indicates the option value that each firm holds to acquire information on $\theta$ and $T$ the optimal learning time, defined as:

$$
T(Q)=\inf \left(t \geq 0 \mid E_{\theta}\left[V\left(Q_{I} ; \theta\right)\right]-V\left(Q_{I} ; 0\right)=\frac{\Phi}{n}+I\left(Q_{I}\right)\right) .
$$

The optimal learning time is thus given by the very moment at which the stock $Q_{I}$ reaches a specific level, i.e., as soon as the value of information exactly outweighs the opportunity cost to acquire it, where the latter consists 
of the cost of information $\frac{\Phi}{n}$ plus the value of the option to wait. ${ }^{8}$

In particular, since (12) is monotonic, we are able to write:

$$
E_{\theta}[V(Q ; \theta)]=\int_{-1}^{\tilde{\theta}(Q)} V_{0}(Q ; \theta) f(\theta) d \theta+\int_{\tilde{\theta}(Q)}^{+1} V_{1}(Q ; \theta) f(\theta) d \theta
$$

where $\tilde{\theta}(Q)=\frac{\hat{Q}}{Q}-1 \in[0, \infty) .{ }^{9}$ Equation (17) shows that, for any given $Q$, the ex-ante value is formed by two terms. The first integral indicates the firm's value when the revealed value of $\theta$ is so low that it is not optimal to invest in quality, while the second integral reflects the case where $\theta$ is found sufficiently high to induce the firm to invest in quality. Using (17), we are able to write the ex-ante value of information on $\theta$ as:

$$
\begin{aligned}
& E_{\theta}[V(Q ; \theta)]-V(Q ; 0)= \\
& \left\{\begin{aligned}
\int_{-1}^{\tilde{\theta}(Q)} V_{0}(Q ; \theta) f(\theta) d \theta+\int_{\tilde{\theta}(Q)}^{+1} V_{1}(Q ; \theta) f(\theta) d \theta-V_{1}(Q ; 0) & \hat{Q}<Q<\infty \\
\int_{-1}^{\tilde{\theta}(Q)} V_{0}(Q ; \theta) f(\theta) d \theta+\int_{\tilde{\theta}(Q)}^{+1} V_{1}(Q ; \theta) f(\theta) d \theta-V_{0}(Q ; 0) & \frac{\hat{Q}}{2}<Q<\hat{Q} \\
\int_{-1}^{+1} V_{0}(Q ; \theta) f(\theta) d \theta-V_{0}(Q ; 0) & \text { for } Q<\frac{\hat{Q}}{2}
\end{aligned}\right.
\end{aligned}
$$

Let us turn now to the solution of (15). Assuming that there exists a value $Q_{I}$ beyond which each firm decides to coordinate spending on $\theta$, we need to distinguish between the case where $Q_{I}$ is below $\hat{Q}$ from the case where $Q_{I}$ is above $\hat{Q}$. In words, starting from $Q<\frac{\hat{Q}}{2}$, if the stock of quality hits for the

\footnotetext{
${ }^{8}$ Note that both $I(Q)$ and $T(Q)$ are functions of $Q$ only, since $E_{\theta}[V(Q ; \theta)]$ is taken over the distribution of $\theta$.

${ }^{9}$ To be precise, since $\frac{d \tilde{Q}(\theta)}{d \theta}<0$ for all $\theta \in[-1,+1]$, by inverting (12) we get:

$$
\tilde{\theta}(Q)=\left\{\begin{array}{cc}
-1 & \text { when } \tilde{Q}(-1)=\infty \\
\frac{\hat{Q}}{Q}-1 & \text { for } \frac{\hat{Q}}{2}<Q<\infty \\
+1 & Q \leq \tilde{Q}(+1)=\frac{\hat{Q}}{2}
\end{array}\right.
$$
}


first time $Q_{I}<\hat{Q}$ the firm maximizes the value of information (18) while it is not investing in quality. On the contrary, if the optimal trigger lies above $\hat{Q}$ then the firm maximizes the value of acquiring $\theta$ having first decided to already invest in quality. This implies that in the first case the solution of (15) must solve the following Bellman equation:

$$
r I=\frac{1}{2} \sigma^{2} Q^{2} I^{\prime \prime} \quad \text { for } Q<Q_{I}<\hat{Q}
$$

while in the second case the Bellman equation becomes:

$$
r I=\frac{1}{2} \sigma^{2} Q^{2} I^{\prime \prime}+\alpha Q I^{\prime} \text { for } \hat{Q}<Q<Q_{I}
$$

where $I^{\prime}$ and $I^{\prime \prime}$ stand for the first and second derivatives with respect to $Q$ respectively.

From which we can prove:

Proposition 3 1) If $\frac{\hat{Q}}{2}<Q<\hat{Q}$, provided that $Q_{I}<\hat{Q}$, the optimal trigger is given by:

$$
\begin{aligned}
\frac{\alpha Q_{I}}{r(r-\alpha)} \int_{\tilde{\theta}\left(Q_{I}\right)}^{+1}(1+\theta) f(\theta) d \theta= & \frac{\beta_{1}}{\beta_{1}-1}\left[\frac{\Phi}{n}+\frac{c}{r}\left[1-F\left(\tilde{\theta}\left(Q_{I}\right)\right)\right]\right] \\
& -\frac{\beta_{1}-\gamma_{2}}{\beta_{1}-1}\left\{\int_{\tilde{\theta}\left(Q_{I}\right)}^{+1} \tilde{B}_{1}(\theta) Q_{I}^{\gamma_{2}} f(\theta) d \theta\right\}
\end{aligned}
$$

2) If $\hat{Q}<Q<\infty$, provided that $Q_{I}>\hat{Q}$, the optimal trigger is given by:

$$
\begin{aligned}
\frac{\alpha Q_{I}}{r(r-\alpha)} \int_{\tilde{\theta}\left(Q_{I}\right)}^{+1}(1+\theta) f(\theta) d \theta= & \frac{\alpha Q_{I}}{r(r-\alpha)}+\left(\frac{\gamma_{1}}{\gamma_{1}-1}\right)\left[\frac{\Phi}{n}-\frac{c}{r} F\left(\tilde{\theta}\left(Q_{I}\right)\right)\right] \quad(22) \\
& +\left(\frac{\beta_{1}-\gamma_{1}}{\gamma_{1}-1}\right) \int_{-1}^{\tilde{\theta}\left(Q_{I}\right)}\left[\tilde{A}_{0}(\theta) Q_{I}^{\beta_{1}}\right] f(\theta) d \theta \\
& -\left(\frac{\gamma_{1}-\gamma_{2}}{\gamma_{1}-1}\right)\left[\int_{\tilde{\theta}\left(Q_{I}\right)}^{+1} \tilde{B}_{1}(\theta) Q_{I}^{\gamma_{2}} f(\theta) d \theta-\hat{B}_{1} Q_{I}^{\gamma_{2}}\right]
\end{aligned}
$$


3) If $Q<\frac{\hat{Q}}{2}$ or $Q \rightarrow \infty$ it will never be optimal for the firms to acquire information on $\theta$.

\section{Proof. See Appendix B}

When the current value of quality is small, the first part of Proposition 3 says that it is worth to acquire information about the true value of $\theta$, on an individual basis, when the expected present value of the extra revenues from the investment in quality covers the opportunity cost due to the sunkness of $\Phi$, the investment cost $c$ and the value of the option to stop investing if the market conditions turn down.

Conversely, the second part of Proposition 3 says that when $Q$ is high enough and the firm is already investing in quality, it is worth to acquire information on $\theta$ only if the expected present value of the extra revenues, having done so, covers the extra revenues that the firm is already getting without information (i.e. $\frac{\alpha Q_{I}}{r(r-\alpha)}=\frac{Q_{I}}{r-\alpha}-\frac{Q_{I}}{r}$ ), plus the opportunity cost to acquire the information, plus the expected opportunity cost to have to wait before investing in the case of bad news about $\theta$ (positive, since $\beta_{1}>\gamma_{1}$ ), and finally minus the difference between the expected option value to abandon the investment that the firm would have acquiring the information and the one that it has without knowing $\theta$. Note that, in this case, the investment cost $c$ enters negatively. This is simply due to the fact that since the firm is investing in quality stopping doing it is seen as a benefit. The value of $Q_{I}$ that satisfies condition $(21)((22))$ and also satisfies $Q_{I}<\hat{Q}\left(Q_{I}>\hat{Q}\right)$ can be found numerically. ${ }^{10}$

Finally, by direct inspection of (21) and (22), it easy to show that if the aggregate level of quality is too low or extremely high (going to infinity) it is never optimal to learn $\theta$. In fact for $Q_{I} \rightarrow \frac{\hat{Q}}{2}$ only good news about $\theta$ may induce the firm to acquire information, i.e., $\tilde{\theta}\left(Q_{I}\right) \rightarrow+1$, and Equation (21)

\footnotetext{
${ }^{10}$ Note that the non-linearity of $(21)$ and $(22)$ does not guarantee that the solution, if it exists, is unique. In the case of multiple solutions, the trigger would be the smaller $Q_{I}$ greater than $Q$.
} 
will never be satisfied. On the other hand, for $Q_{I} \rightarrow \infty$, the option to stop investing becomes negligible and $Q$ is so high that the option to reconsider investment in the face of bad news on $\theta$ disappears (i.e. $\tilde{\theta}\left(Q_{I}\right) \rightarrow-1$ ). The third part of Proposition 3 thus defines the ranges of aggregate quality where it is never optimal to invest in information acquisition.

\section{The information disclosure choice}

The analysis studied the firms' optimal choice of investing in quality. Nevertheless, the analysis provides some indications on whether it would be worthwhile for an external body to acquire information on consumers' valuation of aggregate quality and disclose it to firms. A single firm cannot disclose such information, since that would be considered cheap talk, and a natural benchmark would be a consortium of the industry that could credibly certify the veracity of the information. We will discuss the case of such a "regulator" aiming at maximizing the probability that the firms invest in quality. An example of such a situation might be the case of those consortia that are formed as public entities, characterized by a compulsory membership and that have as a mandate (at least formally), to guarantee members' quality on behalf of public interest, as it is the case, for instance, of professional associations or bodies.

We assume therefore that such a consortium, or body, aims at maximizing the probability of quality adoption by its members. Let $\tilde{P}(\tilde{Q}(\theta) ; Q)$ and $\hat{P}(\hat{Q} ; Q)$ be the probabilities of investing when $\theta$ is revealed and when it is unknown, respectively. In other words, starting at $Q$ in the interior of the range $(0, \tilde{Q}(\theta)]$ and $(0, \hat{Q}], \tilde{P}$ and $\hat{P}$ indicate the probability that the stock of quality reaches the triggers $\tilde{Q}(\theta)$ and $\hat{Q}$, respectively. Obviously, $\hat{P}(\hat{Q} ; Q)<1$ when $Q<\hat{Q}$ and $\hat{P}(\hat{Q} ; Q)=1$ for $Q \geq \hat{Q}$.

We consider two possible cases: 1) neither the consortium nor the firms can learn about consumer perceptions, 2) the consortium does not know $\theta$ 
but can acquire information on consumer perceptions at no cost, and has to decide ex ante whether it is worthwhile to do so assuming that once it obtains the information all members can see it, i.e., the firms will know $\theta .{ }^{11}$

Note that in case 1), when neither the consortium nor the firms can learn about consumer perceptions, $\theta$ cannot be revealed and the two probabilities coincide. In such a case information is irrelevant. The only choice the consortium can make, should it be able to do so, is to induce firms to invest earlier (lower the trigger for investment) by restricting the number of members, or in the case of agricultural goods, delimit the geographic area of the protected origin label in order to decrease the number of firms concerned. These options follow directly from the comparative statics on the investment trigger (8):

$$
\frac{\partial \hat{Q}}{\partial c}>0, \quad \frac{\partial \hat{Q}}{\partial n}>0, \frac{\partial \hat{Q}}{\partial a}=0
$$

As expected, the higher the investment cost, the higher the investment trigger and thus, mutatis mutandis, the higher is the critical level of quality below which firms find it optimal not to invest. Similarly, the number of firms has a negative impact on the investment game, inducing a higher trigger level of quality to invest. The reason is that an increase in the number of firms, coupled with the possible free riding behavior, can only reduce the average quality of the investment and this lowers the positive impact that the investment decision has on each firm's value. In other words, the marginal damage of the free-riding problem more than compensates the positive quality spillover, inducing firms to delay the investment in quality.

Any action that decreases the number of firms would thus decrease the trigger level for investment in quality and hence maximize aggregate quality, as would a subsidy to the firm's cost of investing in quality $(c)$. Two factors

\footnotetext{
${ }^{11}$ Note however that we do not allow firms knowing ex ante that the consortium has the possibility to release such information - in other words, no signalling game is allowed between the consortium and the firms.
} 
explain this straightforward result: average quality is what matters for consumer perceptions, so a higher number of firms decreases average quality, all else equal, and in addition, the more numerous are firms, the worse is the free-riding problem in the dynamic game.

In case 2), the consortium may acquire the information and reveal it to the firms. It has to decide the optimal time to do so, i.e., whether it is best acquiring the information right away and revealing it to all members, or waiting for firms to invest in quality by themselves and then disclosing the information on $\theta$. Hence, the consortium's problem consists of identifying the stock $Q$ that maximizes the following difference:

$\Delta(P(Q))=\left\{\begin{array}{cl}\int_{-1}^{\tilde{\theta}(Q)} \tilde{P}(\tilde{Q}(\theta) ; Q) f(\theta) d \theta+\int_{\tilde{\theta}(Q)}^{+1} 1 f(\theta) d \theta-\hat{P}(\hat{Q} ; Q) & \text { for } Q<\hat{Q} \\ \int_{-1}^{\tilde{\theta}(Q)} \tilde{P}(\tilde{Q}(\theta) ; Q) f(\theta) d \theta+\int_{\tilde{\theta}(Q)}^{+1} 1 f(\theta) d \theta-1 & \text { for } Q \geq \hat{Q}\end{array}\right.$

We can claim the following

Proposition 4 It is never (strictly) optimal to disclose the information on $\theta$. It is indifferent to do so only when $Q=\frac{\hat{Q}}{2}$.

Proof. See Appendix C

The above proposition clearly shows that for the consortium it is never optimal to acquire and disclose the information on consumers' perception even if it were costless do do so. In fact, it is always strictly worse, in the sense that the probability of investing in quality, once the information is revealed, is lower for all possible levels of accumulated quality, with just one specific exception, namely, that exact level of quality for which it would be indifferent to reveal the information since it would have no impact on the probability of an early adoption of quality. The rationale of such a result is the following. When firms are already investing in quality, there is no point in revealing information that might just do harm, in the sense of inducing 
firm to stop investing should they come to know that they have adopted quality too early. What about when firms are not investing? If $Q$ is too low, i.e., below $\frac{\hat{Q}}{2}$, it is not optimal to disclose information since this would not induce any change in investment strategy. Therefore, it might be optimal to disclose information only when quality is in that range for which firms might find it profitable to invest, i.e., when $\frac{\hat{Q}}{2} \leq Q$. Recall that there would be an early adoption of quality only if $\theta$ was in the range for which it delivered "good news", in the sense that once discovered $\theta$ happened to be bigger than its expected value. On the contrary, it would yield "bad news" if it was lower than 0 . Recall that, without any information, the firm would invest at $Q=\hat{Q}$. Let $Q$ be in the range of $\frac{\hat{Q}}{2} \leq Q<\hat{Q}$. As $Q$ reaches $\hat{Q}$ from below, the set of possible good news, which would induce an early adoption, namely, those values of $\theta$ included in the range $0<\theta<\theta(\mathrm{Q})$, shrinks compared to the set of bad news. In other words, as $Q$ reaches the investment trigger, firms are getting closer to the moment in which they would start investing anyhow. Revealing $\theta$ would therefore do only harm to an early adoption of quality, because the set of possible results of the information disclosure on the basis of which they would postpone their investment decision becomes relatively larger than the set of those cases in which they would anticipate the investments. Obviously, with $\theta$ symmetrically distributed, there is just one value of $Q$ for which those sets are equivalent, that is, when the level of quality is at $Q=\frac{\hat{Q}}{2}$.

\section{Conclusion}

We set up a model of collective reputation where firms face two sources of randomness: one related to the overall level of quality, because of the occurrence of random events that affect production, and the other related to consumers' subjective beliefs on average quality. We then analyze the role of information on consumers' perception on the investment in quality in such a 
setting. First we analyze the firms' optimal choice of investment in quality without information on consumers' valuation of the aggregate level of quality and determine the option value related to its investment in quality. There are two opposing effects at work: on the one hand the positive impact on demand of a reputation for quality gives incentives for investment in quality, on the other hand free-riding among firms makes a firm wait until going ahead with its investment. The option value of investment can be negative or positive depending on which effect prevails. Second, we introduce information acquisition. The firm can obtain information on consumers' valuation of quality by paying a fee to a market research company, for example. We identify the conditions on consumers' perception of quality that makes information acquisition increase firms' investment in quality. Finally, we investigate the possibility for a firm consortium or public body that is interested in maximizing quality adoption, to speed up the quality accumulation process by acquiring the information on consumers' perception and revealing it to the firms. We show that it is never optimal to do so, even if the information acquisition were costless, since it would have a negative impact on the probability of an early adoption of quality by the firms. In other words, it is more likely to do harm to quality adoption in the sense that it would induce firms to wait more than they would with no information on consumers' perception. This result depends in particular on the assumption of a symmetric distribution of quality perception, as well as on the assumption of a random walk for the stochastic evolution of quality over time. Far from being ad hoc assumptions, we believe that they allow us to develop the model through a neutral and meaningful set up, which does not introduce any artificial exogenous bias on the quality perception by consumers, on the one hand, and which guarantees that quality can be accumulated only by means of deliberate action by firms through investment, on the other hand. The latter assumption, in particular, seems to describe well those situations of collective reputation building, like the protected geographical labels or the $\mathrm{R} \& \mathrm{D}$ examples that 
we referred to in the introduction, for which it seems meaningful to suppose that there are no systematic windfall gains in the quality building without any intentional and joint effort undertaken by those who are involved in it.

Our model is only a first attempt at investigating the role of information in the framework of stochastic collective reputation. Alternative modelization of quality could also be explored, for example, how firms' investment decisions change when their action may reduce the variance of reputation, instead of the collective reputation itself, as in the present model. We leave such an extension to a future development.

Acknowledgements. The authors thank participants at the EAERE 19th Annual Conference, the 21ème Rencontres de l'Environnement à Besançon, France, and seminar participants at CERNA, Mines Paris Tech, France and at DIEC, University of Genova, Italy, for their comments on previous versions of this paper. Katrin Millock thanks the Department of Economics and Management at the University of Padua for its hospitality during her research stays there.

\section{References.}

Basar, T. and Olsder, G.J., (1995), Dynamic Noncooperative Game Theory, 2d ed., Academic Press, San Diego.

Board, S. and Meyer-ter-Vehn, M., (2011), Reputation for Quality, Working Paper, University of California, Los Angeles.

Bohren, J.A., (2011), Stochastic Games in Continuous Time: Persistent Actions in Long-Run Relationships. Working Paper, University of California, San Diego.

Claude D. and Zaccour, G., (2009), Investment in Tourism Market and Reputation, Journal of Public Economic Theory 11(5), 797-817.

Cox, D.R. and Miller, H.D., (1965), The Theory of Stochastic Processes, Chapman and Hill, London. 
d'Aspremont, C. and Jacquemin, A., (1988), Cooperative and Noncooperative R\&D in Duopoly with Spillovers, American Economic Review 78(5), 1133-1137.

Darby, M.R. and Karni, E., (1973), Free Competition and the Optimal Amount of Fraud, Journal of Law and Economics 16(1), 67-88.

Dilme, F., (2011), Building (and Milking) Trust: Reputation as a Moral Hazard Phenomenon, Working Paper, University of Pennsylvania.

Dixit, A. and Pindyck, R.S., (1994), Investment under Uncertainty, Princeton University Press, Princeton.

Dranove, D. and Jin, G.Z., (2010), Quality Disclosure and Certification: Theory and Practice, Journal of Economic Literature 48(4), 935-963.

Faingold, E. and Sannikov, Y., (2011), Reputation in Continuous-Time Games. Econometrica 79(3), 773-876.

Fleckinger, P., (2007), Collective Reputation and Market Structure: Regulating the Quality vs Quantity Trade-Off, Working Paper, Ecole Polytechnique Cahier no. 2007-26.

Hinloopen, J., Smrkolj, G. and Wagener, F.O.O., (2011), From Mind to Market: A Global, Dynamic Analysis of R\&D. Tinbergen Institute Discussion Paper TI 2011-139/1.

Kamien, M.I., Muller, E. and Zang, I., (1992), Cooperative Joint Ventures and R\&D Cartels, American Economic Review 82, 1293-1306.

Kennedy, P., Laplante, B. and Maxwell, J., (1994), Pollution Policy: The Role of Publicly Provided Information, Journal of Environmental Economics and Management 26 (1), 31-43.

Landon, S. and Smith, C.S., (1997), The Use of Quality and Reputation Indicators by Consumers: The Case of Bordeaux Wine, Journal of Consumer Policy 20(3), 289-323.

Landon, S. and Smith, C.S., (1998), Quality Expectations, Reputation and Price, Southern Economic Journal 64(3), 628-647.

McQuade, T., Salant, S.W. and Winfree, J.A., (2010), Markets with Un- 
traceable Goods of Unknown Quality: A Market Failure Exacerbated by Globalisation, RFF Discussion Paper 09-31.

Murto, P., (2004). Valuing Options to Learn: Optimal Timing of Information Acquisition. Paper presented at Real Options 2004.

Petrakis, E., Sartzetakis, E.S. and Xepapadeas, A., (2005), Environmental Information Provision as a Public Policy Instrument, Contributions to Economic Analysis and Policy 4(1), Article 14.

Sartzetakis, E.S., Xepapadeas, A. and Petrakis, E., (2012), The Role of Information Provision as a Policy Instrument to Supplement Environmental Taxes: Empowering Consumers to Choose Optimally, Environmental and Resource Economics 52(3), 347-368.

Tirole, J., (1996), A Theory of Collective Reputation (with Applications to the Persistence of Corruption and to Firm Quality), Review of Economic Studies 63(1), 1-22.

Winfree J. A. and McCluskey, J. J., (2005), Collective Reputation and Quality, American Journal of Agricultural Economics 87 (1), 206-213.

Wirl, F., (2008), Tragedy of the Commons in a Stochastic Game of a Stock Externality, Journal of Public Economic Theory 10(1), 99-124.

\section{A Appendix A}

The general solution to the differential equations (6) and (7) takes the form: ${ }^{12}$

$$
V_{0}(Q ; 0)=A_{0} Q^{\beta_{1}}+B_{0} Q^{\beta_{2}}+\frac{a+Q}{r} \text { for } Q<\hat{Q}
$$

and

$$
V_{1}(Q ; 0)=A_{1} Q^{\gamma 1}+B_{1} Q^{\gamma_{2}}+\frac{a}{r}+\frac{Q}{r-\alpha}-\frac{c}{r} \text { for } Q>\hat{Q}
$$

\footnotetext{
${ }^{12}$ See Dixit and Pindyck (1994, chapters 6 and 7 ) for a thorough discussion.
} 
where $\beta_{1}, \gamma_{1}>1$ and $\beta_{2}, \gamma_{2}<0$ are the roots of the characteristic equations $Q(\beta)=\frac{1}{2} \sigma^{2} \beta(\beta-1)-r=0$ and $Q(\gamma)=\frac{1}{2} \sigma^{2} \gamma(\gamma-1)+\alpha \gamma-r=0$ respectively. $A_{0}, B_{0}, A_{1}, B_{1}$ are four constants to be determined. Note that under $Q<\hat{Q}$ the first and second terms stand for the value of the option to switch to investment. However, since the value of the option vanishes as $Q \rightarrow 0$, we set $B_{0}=0$. Similarly, under $Q>\hat{Q}$ the option to suspend investment is valueless as $Q \rightarrow \infty$ and then we set $A_{1}=0$. To find the constants $A_{0}, B_{1}$ and the optimal trigger $\hat{Q}$ we impose a matching value condition and smooth pasting at $\hat{Q}$ :

$$
\begin{gathered}
A_{0} \hat{Q}^{\beta_{1}}+\frac{a+\hat{Q}}{r}=B_{1} \hat{Q}^{\gamma_{2}}+\frac{a}{r}+\frac{\hat{Q}}{r-\alpha}-\frac{c}{r} \\
A_{0} \beta_{1} \hat{Q}^{\beta_{1}-1}+\frac{1}{r}=B_{1} \gamma_{2} \hat{Q}^{\gamma_{2}-1}+\frac{1}{r-\alpha}
\end{gathered}
$$


and the incentive constraint ${ }^{13}$

$$
A_{0} \beta_{1} \hat{Q}^{\beta_{1}}+\frac{\hat{Q}}{r}=\frac{c}{\alpha-\alpha \frac{n-1}{n}}
$$

Solving the system [24-26] yields the following:

$$
\hat{Q}=\frac{\left(\beta_{1}-\gamma_{2}\right) \frac{r n}{\alpha}-\gamma_{2} \beta_{1}}{\left(\beta_{1}-\gamma_{2}\right)-\beta_{1}\left(\gamma_{2}-1\right) \frac{\alpha}{r-\alpha}} c>0
$$

and:

$$
\begin{aligned}
& \hat{A}_{0}=\left[\frac{n c}{\alpha}-\frac{\hat{Q}}{r}\right] \frac{\hat{Q}^{-\beta_{1}}}{\beta_{1}} \\
& \hat{B}_{1}=\left[\frac{n c}{\alpha}-\frac{\hat{Q}}{r-\alpha}\right] \frac{\hat{Q}^{-\gamma_{2}}}{\gamma_{2}}
\end{aligned}
$$

Q.E.D.

$$
\begin{aligned}
& \begin{array}{l}
13 \\
k
\end{array} \text { This condition follows from the maximization of Equation (5). Each firm will invest } \\
& \frac{1}{2} \sigma^{2} Q^{2} V^{\prime \prime}+g\left(1+\sum_{j=2}^{n} k_{j}\right) Q V^{\prime}+p(Q ; 0)-c \geq \frac{1}{2} \sigma^{2} Q^{2} V^{\prime \prime}+g\left(\sum_{j=2}^{n} k_{j}\right) Q V^{\prime}+p(Q ; 0)
\end{aligned}
$$

which at $\hat{Q}$, reduces to

$$
\begin{aligned}
g\left(1+\sum_{j=2}^{n} k_{j}\right) \hat{Q} V^{\prime}-c & =g\left(\sum_{j=2}^{n} k_{j}\right) \hat{Q} V^{\prime} \\
\hat{Q} V^{\prime} & =\frac{c}{g\left(1+\sum_{j=2}^{n} k_{j}\right)-g\left(\sum_{j=2}^{n} k_{j}\right)}
\end{aligned}
$$

Then by symmetry we obtain

$$
\hat{Q} V I=\frac{c}{g(n)-g(n-1)}
$$

The marginal gain of investing one more unit in quality should be equal to the marginal cost. 


\section{B Appendix B}

For $Q_{I}$ below $\hat{Q}$, the Bellman equation of (15) is:

$$
r I=\frac{1}{2} \sigma^{2} Q^{2} I^{\prime \prime} \quad \text { for } Q<Q_{I}<\hat{Q}
$$

On the contrary, if the firm acquires the information while investing in quality the Bellman equation of (15) becomes:

$$
r I=\frac{1}{2} \sigma^{2} Q^{2} I^{\prime \prime}+\alpha Q I^{\prime} \text { for } \hat{Q}<Q<Q_{I}
$$

Consider the first case. The general solution for $I$ takes the form:

$$
I(Q)=M_{0} Q^{\beta_{1}}+M_{1} Q^{\beta_{2}} \text { for } Q<Q_{I}
$$

where $\beta_{1}>1$ and $\beta_{2}<0$ are the roots of the characteristic equations $Q(\beta)=$ $\frac{1}{2} \sigma^{2} \beta(\beta-1)-r=0$. However, since the value of the option to acquire the information vanishes as $Q \rightarrow 0$ we set $M_{1}=0$. To find the constant $M_{0}$ and the optimal trigger $Q_{I}$ we impose a matching value condition and smooth pasting at $Q_{I}$. Using (18), we have

$$
\begin{aligned}
M_{0} Q_{I}^{\beta_{1}}= & \int_{-1}^{\tilde{\theta}\left(Q_{I}\right)} V_{0}\left(Q_{I} ; \theta\right) f(\theta) d \theta \\
& +\int_{\tilde{\theta}\left(Q_{I}\right)}^{+1} V_{1}\left(Q_{I} ; \theta\right) f(\theta) d \theta-V_{0}\left(Q_{I} ; 0\right)-\frac{\Phi}{n}
\end{aligned}
$$

and: 


$$
\begin{aligned}
M_{0} \beta_{1} Q_{I}^{\beta_{1}-1}= & \frac{d \tilde{\theta}\left(Q_{I}\right)}{d Q_{I}}\left[V_{0}\left(Q_{I} ; \tilde{\theta}\left(Q_{I}\right)\right) f\left(\tilde{\theta}\left(Q_{I}\right)\right)\right] \\
& +\int_{-1}^{\tilde{\theta}\left(Q_{I}\right)} V_{0}^{\prime}\left(Q_{I} ; \theta\right) f(\theta) d \theta \\
& -\frac{d \tilde{\theta}\left(Q_{I}\right)}{d Q_{I}}\left[V_{1}\left(Q_{I} ; \tilde{\theta}\left(Q_{I}\right)\right) f\left(\tilde{\theta}\left(Q_{I}\right)\right)\right] \\
& +\int_{\tilde{\theta}\left(Q_{I}\right)}^{+1} V_{1}^{\prime}\left(Q_{I} ; \theta\right) f(\theta) d \theta-V_{0}^{\prime}\left(Q_{I} ; 0\right)
\end{aligned}
$$

Since by $(13) V_{0}\left(Q_{I} ; \tilde{\theta}\left(Q_{I}\right)\right)=V_{1}\left(Q_{I} ; \tilde{\theta}\left(Q_{I}\right)\right)$, then (31) reduces to:

$$
\begin{aligned}
M_{0} Q_{I}^{\beta_{1}}= & \int_{-1}^{\tilde{\theta}\left(Q_{I}\right)} \frac{Q_{I}}{\beta_{1}} V_{0}^{\prime}\left(Q_{I} ; \theta\right) f(\theta) d \theta \\
& +\int_{\tilde{\theta}\left(Q_{I}\right)}^{+1} \frac{Q_{I}}{\beta_{1}} V_{1}^{\prime}\left(Q_{I} ; \theta\right) f(\theta) d \theta-\frac{Q_{I}}{\beta_{1}} V_{0}^{\prime}\left(Q_{I} ; 0\right)
\end{aligned}
$$

Substituting in (30), we get:

$$
\begin{aligned}
& \int_{-1}^{\tilde{\theta}\left(Q_{I}\right)} V_{0}\left(Q_{I} ; \theta\right) f(\theta) d \theta \\
& +\int_{\tilde{\theta}\left(Q_{I}\right)}^{+1} V_{1}\left(Q_{I} ; \theta\right) f(\theta) d \theta-V_{0}\left(Q_{I} ; 0\right)-\frac{\Phi}{n} \\
= & \int_{-1}^{\tilde{\theta}\left(Q_{I}\right)} \frac{Q_{I}}{\beta_{1}} V_{0}^{\prime}\left(Q_{I} ; \theta\right) f(\theta) d \theta \\
& +\int_{\tilde{\theta}\left(Q_{I}\right)}^{+1} \frac{Q_{I}}{\beta_{1}} V_{1}^{\prime}\left(Q_{I} ; \theta\right) f(\theta) d \theta-\frac{Q_{I}}{\beta_{1}} V_{0}^{\prime}\left(Q_{I} ; 0\right)
\end{aligned}
$$

Substituting in for $V_{0}\left(Q_{I} ; \theta\right)$ and $V_{1}\left(Q_{I} ; \theta\right)$, and their derivatives gives: 


$$
\begin{aligned}
& \int_{-1}^{\tilde{\theta}\left(Q_{I}\right)}\left[\tilde{A}_{0}(\theta) Q_{I}^{\beta_{1}}+\frac{a+(1+\theta) Q_{I}}{r}\right] f(\theta) d \theta \\
+ & \int_{\tilde{\theta}\left(Q_{I}\right)}^{+1}\left[\tilde{B}_{1}(\theta) Q_{I}^{\gamma_{2}}+\frac{a}{r}+\frac{(1+\theta) Q_{I}}{r-\alpha}-\frac{c}{r}\right] f(\theta) d \theta \\
& -\left[\hat{A}_{0} Q_{I}^{\beta_{1}}+\frac{a+Q_{I}}{r}\right]-\frac{\Phi}{n} \\
= & \int_{-1}^{\tilde{\theta}\left(Q_{I}\right)} \frac{Q_{I}}{\beta_{1}}\left[\tilde{A}_{0}(\theta) \beta_{1} Q_{I}^{\beta_{1}-1}+\frac{(1+\theta)}{r}\right] f(\theta) d \theta \\
& +\int_{\tilde{\theta}\left(Q_{I}\right)}^{+1} \frac{Q_{I}}{\beta_{1}}\left[\tilde{B}_{1}(\theta) \gamma_{2} Q_{I}^{\gamma_{2}-1}+\frac{(1+\theta)}{r-\alpha}\right] f(\theta) d \theta \\
& -\frac{Q_{I}}{\beta_{1}}\left[\hat{A}_{0} \beta_{1} Q_{I}^{\beta_{1}-1}+\frac{1}{r}\right]
\end{aligned}
$$

or:

$$
\begin{aligned}
& Q_{I} \int_{\tilde{\theta}\left(Q_{I}\right)}^{+1}(1+\theta) f(\theta) d \theta \\
= & \frac{\beta_{1}}{\beta_{1}-1} \frac{(r-\alpha)}{\alpha}\left[c\left[1-F\left(\tilde{\theta}\left(Q_{I}\right)\right]+\frac{r \Phi}{n}\right]\right. \\
& -\frac{\beta_{1}-\gamma_{2}}{\beta_{1}-1} \frac{(r-\alpha)}{\alpha}\left\{\int_{\tilde{\theta}\left(Q_{I}\right)}^{+1} r \tilde{B}_{1}(\theta) Q_{I}^{\gamma_{2}} f(\theta) d \theta\right\}
\end{aligned}
$$

It is easy to show that if $Q$ is below $\frac{\hat{Q}}{2}$ it is never optimal for the firm to acquire information about the true value of $\theta$. This can be seen noting that if we look for $Q_{I} \simeq \frac{\hat{Q}}{2}$, i.e., $\tilde{\theta}\left(Q_{I}\right) \simeq+1$, the expression above is never satisfied.

Let us turn now to the solution of (29). For this case, the general solution for $I$ takes the form:

$$
I(Q)=N_{0} Q^{\gamma_{1}}+N_{1} Q^{\gamma_{2}} \text { for } Q<Q_{I}
$$


where $\gamma_{1}>1$ and $\gamma_{2}<0$ are the roots of the characteristic equations $Q(\gamma)=$ $\frac{1}{2} \sigma^{2} \gamma(\gamma-1)+\alpha \gamma-r=0$. However, since the value of the option to acquire the information vanishes as $Q \rightarrow 0$ we set $N_{1}=0$, and to find the constant $N_{0}$ and the optimal trigger $Q_{l}$ we impose the matching value condition and smooth pasting at $Q_{I}$. Using (18), we get

$$
\begin{aligned}
N_{0} Q_{I}^{\gamma_{1}}= & \int_{-1}^{\tilde{\theta}\left(Q_{I}\right)} V_{0}\left(Q_{I} ; \theta\right) f(\theta) d \theta \\
& +\int_{\tilde{\theta}\left(Q_{I}\right)}^{+1} V_{1}\left(Q_{I} ; \theta\right) f(\theta) d \theta-V_{1}\left(Q_{I} ; 0\right)-\frac{\Phi}{n}
\end{aligned}
$$

and:

$$
\begin{aligned}
N_{0} \gamma_{1} Q_{I}^{\gamma_{1}-1}= & \frac{d \tilde{\theta}\left(Q_{I}\right)}{d Q_{I}}\left[V_{0}\left(Q_{I} ; \tilde{\theta}\left(Q_{I}\right)\right) f\left(\tilde{\theta}\left(Q_{I}\right)\right)\right] \\
& +\int_{-1}^{\tilde{\theta}\left(Q_{I}\right)} V_{0}^{\prime}\left(Q_{I} ; \theta\right) f(\theta) d \theta+ \\
& -\frac{d \tilde{\theta}\left(Q_{I}\right)}{d Q_{I}}\left[V_{1}\left(Q_{I} ; \tilde{\theta}\left(Q_{I}\right)\right) f\left(\tilde{\theta}\left(Q_{I}\right)\right)\right]+ \\
& \int_{\tilde{\theta}\left(Q_{I}\right)}^{+1} V_{1}^{\prime}\left(Q_{I} ; \theta\right) f(\theta) d \theta-V_{1}^{\prime}\left(Q_{I} ; 0\right)
\end{aligned}
$$

Since by $(13) V_{0}\left(Q_{I} ; \tilde{\theta}\left(Q_{I}\right)\right)=V_{1}\left(Q_{I} ; \tilde{\theta}\left(Q_{I}\right)\right)$, then $(33)$ simplifies to:

$$
\begin{aligned}
N_{0} Q_{I}^{\gamma_{1}}= & \int_{-1}^{\tilde{\theta}\left(Q_{I}\right)} \frac{Q_{I}}{\gamma_{1}} V_{0}^{\prime}\left(Q_{I} ; \theta\right) f(\theta) d \theta \\
& +\int_{\tilde{\theta}\left(Q_{I}\right)}^{+1} \frac{Q_{I}}{\gamma_{1}} V_{1}^{\prime}\left(Q_{I} ; \theta\right) f(\theta) d \theta-\frac{Q_{I}}{\gamma_{1}} V_{1}^{\prime}\left(Q_{I} ; 0\right)
\end{aligned}
$$

Substituting in (32), we get: 


$$
\begin{aligned}
& \int_{-1}^{\tilde{\theta}\left(Q_{I}\right)} V_{0}\left(Q_{I} ; \theta\right) f(\theta) d \theta \\
& +\int_{\tilde{\theta}\left(Q_{I}\right)}^{+1} V_{1}\left(Q_{I} ; \theta\right) f(\theta) d \theta-V_{1}\left(Q_{I} ; 0\right)-\frac{\Phi}{n} \\
= & \int_{-1}^{\tilde{\theta}\left(Q_{I}\right)} \frac{Q_{I}}{\gamma_{1}} V_{0}^{\prime}\left(Q_{I} ; \theta\right) f(\theta) d \theta \\
& +\int_{\tilde{\theta}\left(Q_{I}\right)}^{+1} \frac{Q_{I}}{\gamma_{1}} V_{1}^{\prime}\left(Q_{I} ; \theta\right) f(\theta) d \theta-\frac{Q_{I}}{\gamma_{1}} V_{0}^{\prime}\left(Q_{I} ; 0\right)
\end{aligned}
$$

Substituting in for $V_{0}\left(Q_{I} ; \theta\right)$ and $V_{1}\left(Q_{I} ; \theta\right)$, and their derivatives:

$$
\begin{aligned}
& \int_{-1}^{\tilde{\theta}\left(Q_{I}\right)}\left[\tilde{A}_{0}(\theta) Q_{I}^{\beta_{1}}+\frac{a+(1+\theta) Q_{I}}{r}\right] f(\theta) d \theta \\
& +\int_{\tilde{\theta}\left(Q_{I}\right)}^{+1}\left[\tilde{B}_{1}(\theta) Q_{I}^{\gamma_{2}}+\frac{a}{r}+\frac{(1+\theta) Q_{I}}{r-\alpha}-\frac{c}{r}\right] f(\theta) d \theta \\
& -\left[\hat{B}_{1} Q_{I}^{\gamma_{2}}+\frac{a}{r}+\frac{Q_{I}}{r-\alpha}-\frac{c}{r}\right]-\frac{\Phi}{n} \\
= & \int_{-1}^{\tilde{\theta}\left(Q_{I}\right)} \frac{Q_{I}}{\gamma_{1}}\left[\tilde{A}_{0}(\theta) \beta_{1} Q_{I}^{\beta_{1}-1}+\frac{(1+\theta)}{r}\right] f(\theta) d \theta \\
& +\int_{\tilde{\theta}\left(Q_{I}\right)}^{+1} \frac{Q_{I}}{\gamma_{1}}\left[\tilde{B}_{1}(\theta) \gamma_{2} Q_{I}^{\gamma_{2}-1}+\frac{(1+\theta)}{r-\alpha}\right] f(\theta) d \theta \\
& -\frac{Q_{I}}{\gamma_{1}}\left[\hat{B}_{1} \gamma_{2} Q_{I}^{\gamma_{2}-1}+\frac{1}{r-\alpha}\right]
\end{aligned}
$$


or:

$$
\begin{aligned}
& Q_{I}\left[1-\int_{\tilde{\theta}\left(Q_{I}\right)}^{+1}(1+\theta) f(\theta) d \theta\right] \\
= & \left(\frac{\gamma_{1}}{\gamma_{1}-1}\right) \frac{(r-\alpha)}{\alpha}\left[c F\left(\tilde{\theta}\left(Q_{I}\right)-\frac{r \Phi}{n}\right]\right. \\
& +\frac{(r-\alpha)}{\alpha}\left(\frac{\gamma_{1}-\beta_{1}}{\gamma_{1}-1}\right) \int_{-1}^{\tilde{\theta}\left(Q_{I}\right)}\left[r \tilde{A}_{0}(\theta) Q_{I}^{\beta_{1}}\right] f(\theta) d \theta \\
& -\left(\frac{\gamma_{1}-\gamma_{2}}{\gamma_{1}-1}\right) \frac{(r-\alpha)}{\alpha} r\left[\hat{B}_{1} Q_{I}^{\gamma_{2}}-\int_{\tilde{\theta}\left(Q_{I}\right)}^{+1} \tilde{B}_{1}(\theta) Q_{I}^{\gamma_{2}} f(\theta) d \theta\right]
\end{aligned}
$$

If we are looking for an optimal trigger $Q_{I} \gg \hat{Q}$, i.e. $\tilde{\theta}\left(Q_{I}\right) \simeq-1$, the expression above tends to:

$$
0=\left(\frac{\gamma_{1}}{\gamma_{1}-1}\right) \frac{\Phi}{n}
$$

which is never satisfied for finite n. Q.E.D.

\section{Appendix $\mathrm{C}$}

Proof of Proposition 4:

Consider first the case when $Q \geq \hat{Q}$. From Equation (23), it is easy to see that in this case the objective function is always negative:

$$
\Delta(P(Q))=\int_{-1}^{\tilde{\theta}(Q)} \tilde{P}(\tilde{Q}(\theta) ; Q) f(\theta) d \theta-F(\tilde{\theta}(Q))<0
$$

where $\tilde{P}(\tilde{Q}(\theta) ; Q)<1$.

Next consider the case when $\frac{\hat{Q}}{2} \leq Q<\hat{Q}$. Recall that for a generic GBM, s.t. $d x=\alpha x d t+\sigma x d z$, the probability of reaching an upper trigger value $x^{*}$ 
is given by (Cox and Miller, 1965):

$$
\operatorname{Pr}\left(x^{*}, x\right)= \begin{cases}1 & \text { if } 2 \alpha / \sigma^{2} \geq 1 \\ \left(\frac{x^{*}}{x}\right)^{\left(2 \alpha / \sigma^{2}\right)-1} & \text { if } 2 \alpha / \sigma^{2}<1\end{cases}
$$

Starting at $x$ in the interior of the range $\left(0, x^{*}\right]$, after a "sufficient" long interval of time the process is sure to hit the trigger $x^{*}$ if the trend is positive and sufficiently large with respect to the uncertainty. However, if $\alpha$ is positive but low with respect to the uncertainty or it is negative, the process may drift away and never hit $x^{*}$. Applying the expression in (34) to Equation (23) with $\alpha=0$ we obtain:

$$
\begin{aligned}
\Delta(P(Q)) & =\int_{-1}^{\tilde{\theta}(Q)}\left(\frac{Q}{\tilde{Q}(\theta)}\right) f(\theta) d \theta+\int_{\tilde{\theta}(Q)}^{+1} 1 f(\theta) d \theta-\left(\frac{Q}{\hat{Q}}\right) \\
& =[1-F(\tilde{\theta}(Q))]\left[1-\left(\frac{Q}{\hat{Q}}\right)\right]+\left(\frac{Q}{\hat{Q}}\right) \int_{-1}^{\tilde{\theta}(Q)} \theta f(\theta) d \theta
\end{aligned}
$$

We see that $\Delta\left(P\left(\frac{\hat{Q}}{2}\right)\right)=0$ and

$\Delta^{\prime}(P(Q))=\left(\frac{1}{\hat{Q}}\right)\left[\int_{-1}^{\tilde{\theta}(Q)} \theta f(\theta) d \theta-[1-F(\tilde{\theta}(Q))]\right]<0$, for all $\frac{\hat{Q}}{2}<Q<\hat{Q}$

Then $Q=\frac{\hat{Q}}{2}$ is the single root of Equation 35. Q.E.D. 